\title{
Lu-Hf изотопная систематика циркона из плагиогнейсов Кольской сверхглубокой скважины
}

\section{Ветрин В.P.}

Геологический институт КНЦ РАН, Anamuть

ФГБУ ИМГРЭ, Москва, vetrin@geoksc.apatity.ru

Аннотация. Приведены результаты изучения изотопных Lu-Hf и Sm-Nd систем, соответственно, в цирконе и вмещающих плагиогнейсах архейского комплекса Кольской сверхглубокой скважины СГ-3 (69²5' с.ш., 3044' в.д.), пробуренной в северо-западной части Мурманской области. Исследованы кристаллы циркона из плагиогнейсов 8-й толщи (обр. 26, глубина 10780 м) и 10-й толщи (обр. 43, глубина 11778 м). Согласованность Hf- и Nd- изотопных систем в цирконе и породе определяет магматический генезис ядер и оболочек, кристаллизовавшихся в равновесии с силикатной матрицей породы. Циркон метаморфических кайм по величине отношения ${ }^{176} \mathrm{Hf} /{ }^{177} \mathrm{Hf}$ in близок с ядрами и оболочками кристаллов, что свидетельствует о формировании метаморфических кайм кристаллов циркона из плагиогнейсов СГ-3 главным образом в условиях закрытой системы.

Ключевые слова: Кольская сверхглубокая скважина, плагиогнейсы, циркон, Lu-Hf и Sm-Nd изотопные системы.

\section{Lu-Hf isotope systematics of zircon from plagiogneisses of the Kola Superdeep Borehole}

\author{
Vetrin V.R. \\ Geological Institute, Kola Science Centre of RAS, Apatity \\ Institute of Mineralogy, Geochemistry and Crystal Chemistry of Rare Elements, Moscow
}

\begin{abstract}
The article provides results of Lu-Hf and Sm-Nd isotope systems investigation in zircon (LuHf) and plagiogneisses (Sm-Nd) of an Archaean complex of the Kola Superdeep Borehole SD-3 (69 ${ }^{\circ} 25^{\prime}$ n.1., $30^{\circ} 44^{\prime}$ e.1.), drilled in the northwest part of the Murmansk region. Zircon crystals from plagiogneisses of the 8th suite are studied (sample 26, depth is $10780 \mathrm{~m}$ ) and the 10th suite (sample 43, depth is $11778 \mathrm{~m}$ ). The coherence of Hfand Nd-of isotope systems in zircon and rocks indicates the magmatic genesis of the cores and covers crystallized in equilibrium with a silicate matrix of rock. Zircon of metamorphic borders in relation size ${ }^{176} \mathrm{Hf} /{ }^{177} \mathrm{Hf}$ in is close to cores and covers of crystals that demonstrates formation of metamorphic borders mainly in the conditions of the closed system.
\end{abstract}

Key words: Kola Superdeep Borehole, plagiogneisses, zircon, Lu-Hf and Sm-Nd isotope systems.

В строении докембрийской земной коры существенную роль играют породы тоналиттрондьемит-гранодиоритового состава (ТТГ), известные также под названием плагиогнейсы или «серые гнейсы». Породы испытали один или несколько этапов метаморфизма и образованы метаморфогенными парагенезисами породообразующих минералов. Одним из реликтовых минералов протолитов плагиогнейсов является циркон магматического генезиса. В ряде случаев его кристаллы содержат расплавные включения, определяющие состав и эволюцию исходных магм (Thomas et al., 2003). Циркон устойчив к механическим воздействиям, слабо взаимодействует с расплавами и флюидами, имеет высокую температуру закрытия U-Th-Pb и Lu-Hf изотопных систем, вследствие чего является перспективным геохронометром и маркером петрологических процессов. В то же время необходимым условием изучения процессов магматизма и метаморфизма является соответствие полученных данных конкретным геологическим событиям. Для решения поставленных задач требуется определение генетических типов циркона на основании изучения морфологии кристаллов, их внутреннего строения, состава включений, редкоэлементного и изотопного состава.

В настоящем сообщении приведены результаты изучения циркона из плагиогнейсов архейского комплекса Кольской сверхглубокой скважины СГ-3 (69²5'с.ш., 3044'в.д.), пробуренной в 
породах северной части палеопротерозойской Печенгской структуры в северо-западной части Мурманской области. Определение генетических типов циркона выполнено на основании его Lu-Hf изотопного состава и $\mathrm{Sm}-\mathrm{Nd}$ изотопной систематики вмещающих плагиогнейсов, а также по составу захваченных кристаллами расплавных и газово-жидких включений.

\section{Геология и петрология плагиогнейсов}

Породы архейского комплекса СГ-3 вскрыты на глубинах 6842-12262 м и образуют 5 ритмов, нижние части которых (сверху вниз: 2-я, 4-я, 6-я, 8-я, 10-я толщи) сложены метавулканитами дацитплагиориодацитового состава (плагиогнейсами), занимающими 45 \% разреза (Кольская сверхглубокая.., 1984; 1998). Образование исходных магм плагиогнейсов СГ-3 предполагается за счет плавления метабазитовых источников в равновесии с гранатсодержащим реститом при $\mathrm{P} \geq 10-15$ кбар (Ветрин и др., 2003).

\section{Изученные образцы}

Исследованы кристаллы циркона из плагиогнейсов 8-й толщи (обр. 26, глубина 10780 м) и 10-й толщи (обр. 43, глубина 11778 м). Образцы плагиогнейсов представлены среднезернистыми гнейсовидными породами, состоящими из олигоклаза (50-60 \%), микроклина (5-7 \%), кварца (25-30 \%), биотита (5-10 \%), эпидота, титанита, апатита, алланита, циркона, магнетита. Кристаллы циркона включены преимущественно в зерна кварца, реже в зерна плагиоклаза, апатита или приурочены к интерстициальным промежуткам породы. Структура пород гранобластовая, бластогранитовая, с отчетливо проявленным идиоморфизмом плагиоклаза по отношению к кварцу и микроклину. По химическому составу породы относятся к высокоглиноземистому типу $\left(\mathrm{Al}_{2} \mathrm{O}_{3}>14.5 \%\right.$ ) с ASI $\left(\mathrm{Al}_{2} \mathrm{O}_{3} / \mathrm{CaO}+\mathrm{Na}_{2} \mathrm{O}+\mathrm{K}_{2} \mathrm{O}\right.$, мол. кол-ва) от 0.99 до 1.13 , и соответствуют плагиориодациту (трондьемиту) или дациту (тоналиту).

\section{Морфология и этапы образования кристаллов циркона}

Кристаллы циркона из плагиогнейсов СГ-3 имеют однородное или сложное строение и в последнем случае состоят из ядер, занимающих преобладающую часть объема зерен, оболочек и незональных кайм $[6-8,2]$. Кристаллизация ядерных частей кристаллов происходила в интервале времени от 2887 до 2812 млн. лет для плагиогнейсов 8-й толщи, и от 2880 до 2830 млн. лет для ТТГ 10-й толщи, и конкордантный возраст ядер определен, соответственно, в $2857 \pm 9$ и $2852 \pm 4$ млн. лет. Образование оболочек кристаллов (соответственно, $2810 \pm 10$ и $2831 \pm 9$ млн. лет) предполагается в результате излияния на поверхность и быстрой кристаллизации расплавов. При неоархейском метаморфизме ( $2770 \pm 10$ и $2692 \pm 5$ млн. лет) в периферических частях зерен были образованы незональные каймы и обособленные изометричные сложноограненные кристаллы (Чупин и др., 2005; 2006). В то же время длительный интервал кристаллизации ядерных частей кристаллов, а также морфологические особенности зерен позволяют предполагать их образование и в результате захвата магмой ксеногенных кристаллов циркона из вмещающих пород. Трактовка генезиса оболочек кристаллов также не однозначна, и наряду с магматическим генезисом допускается их образование в процессе гранулитового метаморфизма.

\section{Lu-Hf систематика циркона}

При широком интервале вариаций Hf- изотопных характеристик, ядра и оболочки кристаллов циркона из плагиогнейсов имеют сходные средние значения ${ }^{176} \mathrm{Hf} /{ }^{177} \mathrm{Hf}$ in , свидетельствующие об их близком по составу источнике (Ветрин и др., 2016). Циркон метаморфических кайм по величине этого отношения и в пределах аналитических ошибок близок с ядрами и оболочками кристаллов, что свидетельствует, вероятно, о формировании метаморфических кайм кристаллов циркона из плагиогнейсов СГ-3 главным образом в условиях закрытой системы.

\section{Обсуждение результатов}

При реконструкции генетических типов кристаллов циркона целесообразно использование изотопных Lu-Hf и Sm-Nd систем, ведущих себя когерентно в процессах магматической дифферен- 
циации, с положительной корреляцией начальных изотопных отношений $\varepsilon \mathrm{Nd}(\mathrm{T})$ в породе и $\varepsilon \mathrm{Hf}(\mathrm{T})$ в породе или цирконе (Vervoort, Blichert-Toft, 1999; Blichert-Toft, Albarede, 1997; Лохов и др., 2009). Графически указанная зависимость поведения изотопных систем выражается линией с параметром $\varepsilon \mathrm{Hf}(\mathrm{T})=1.36 \mathrm{x} \varepsilon \mathrm{Nd}(\mathrm{T})+3.0$, получившей название terrestrial array, или $\mathrm{TA}$, и с учетом дисперсий определения изотопных параметров - полосой ТА, имеющей ширину порядка 2-4 единиц эпсилон (рис.1). Захваченные (реликтовые) кристаллы циркона, имеющие в сравнении с породой более древний возраст, имеют повышенную величину $\varepsilon \mathrm{Nd}(\mathrm{T})$, и на диаграмме должны располагаться правее и ниже поля ТА. По сравнению с магматическим цирконом кристаллы метаморфического генезиса при их меньшем возрасте и, соответственно, пониженных значениях $\varepsilon \mathrm{Nd}(\mathrm{T})$ имеют близкий, или как правило более радиогенный состав Нf. Содержание радиогенной компоненты определяется вкладом вещества их магматических предшественников и количеством радиогенного ${ }^{176} \mathrm{Hf}$, полученного цирконом при диффузионном обмене c Lu- содержащими темноцветными минералами породы - гранатом, пироксенами, амфиболом, биотитом.

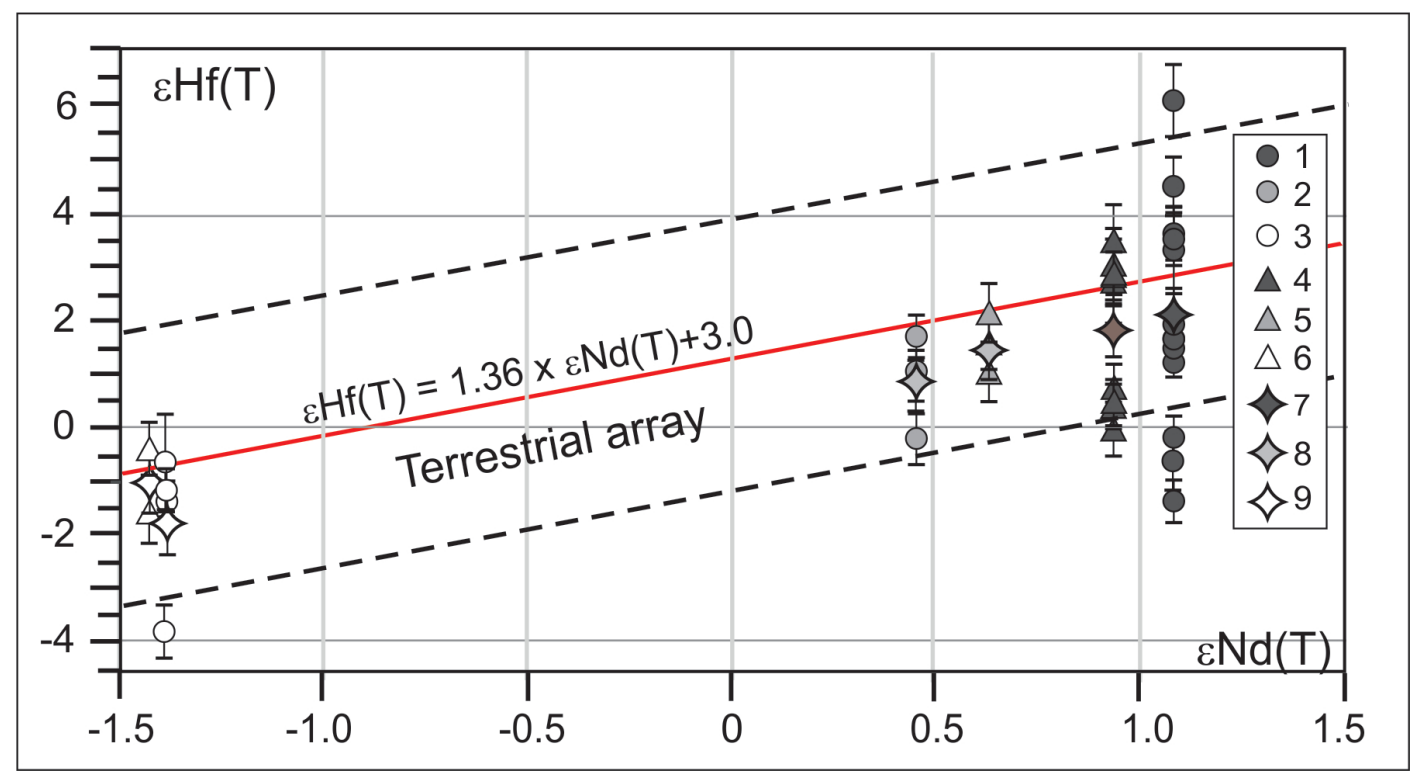

Рис.1. Изотопная Nd-Hf систематика циркона из плагиогнейсов СГ-3.

1-3 и 4-6-соответственно, обр. 26 и 43 (1, 4 - ядра, 2, 5 - оболочки, 3, 6 - каймы), 7-9 - средние значения для ядер, оболочек и кайм. Вертикальные линии у значков- погрешности определения єНf(Т) на уровне $1 \sigma$. Результаты определения изотопного состава Нf в цирконе и Nd в породе приведены в (Ветрин и др., 2003; 2016).

Fig. 1. Isotope Nd-Hf systematics of zircon from SG-3 plagiogneiss. 1-3 and 4 - 6 - respectively, samples 26 and 43 (1, 4-cores, 2, 5-covers, 3, 6 - borders), 7-9-average values for cores, covers and borders.

На диаграмме в координатах $\varepsilon \mathrm{Nd}(\mathrm{T})-\varepsilon \mathrm{Hf}(\mathrm{T})$ точки составов ядер и оболочек изученных кристаллов циркона образуют вертикальные тренды с приуроченностью их средних значений к центральным частям поля ТА. Нахождение точек состава в пределах поля ТА определяется согласованностью Hf- и Nd- изотопных систем в цирконе и породе, что наряду с наличием в кристаллах расплавных включений плагиориодацит-риолитового состава (Чупин и др., 2009) достоверно определяет магматический генезис ядер и оболочек, кристаллизовавшихся в равновесии с силикатной матрицей породы.

Циркон метаморфических кайм и сложноограненных изометрических кристаллов имеет пониженные значения $\varepsilon \mathrm{Nd}(\mathrm{T})$ и $\varepsilon \mathrm{Hf}(\mathrm{T})$, и преобладающая часть точек его состава располагается в центральной части поля ТА, что более свойственно для циркона магматического генезиса. В то же время заведомо метаморфогенное происхождение зерен поздней генерации циркона определяется отсутствием в них расплавных включений и наличием лишь газово-жидких включений водных растворов (Чупин и др., 2005). Когерентность изотопных параметров метаморфогенных зерен циркона 
с породой объясняется, вероятно, образованием кайм главным образом за счет вещества ядер и оболочек кристаллов магматического генезиса. Поскольку кристаллы циркона в плагиогнейсах СГ-3 включены главным образом в зерна плагиоклаза и кварца, не содержащих значимых количеств $\mathrm{Lu}$, это способствовало сохранению изотопного состава магматических частей кристаллов при образовании метаморфических кайм.

\section{Выводы}

Приведенные результаты изучения изотопных составов Hf в цирконе и $\mathrm{Nd}$ в породе показывает достоверность определения по ним различных генетических типов циркона. Существенную помощь может быть получена при исследовании состава расплавных и газово-жидких включений в кристаллах циркона.

Исследования выполнены по теме НИР 0226-2019-0052 при частичной поддержке РФФИ (грант 16-05-00756а) и госконтракта № 13/17-1.

\section{Литература}

1. Ветрин В.Р., Туркина О.М., Ладден Дж., Деленицин А.А. Геохимия и реконструкция состава протолитов фундамента Печенгского палеорифта. Петрология. 2003. Т. 11. № 2. С. 196-224.

2. Ветрин В.Р., Белоусова Е.А., Чупин В.П. Редкие элементы и Lu-Hf изотопная систематика циркона из плагиогнейсов Кольской сверхглубокой скважины: вещество палеоархейской коры в мезоархейских метавулканитах. Геохимия. 2016. № 1. С. 105-125.

3. Кольская сверхглубокая. Исследование глубинного строения континентальной коры с помощью бурения Кольской сверхглубокой скважины / Под ред. Козловского Е.А. / М: Недра. 1984. 490 с.

4. Кольская сверхглубокая. Научные результаты и опыт исследования / Под ред. Орлова В.П. и Лаверова Н.П. / М: Технонефтегаз. 1998. 260 с.

5. Лохов К.И., Салтыкова Т.Е., Капитонов И.Н., Богомолов Е.С., Сергеев С.А., Шевченко С.С. Корректная интерпретация $\mathrm{U}-\mathrm{Pb}$ возраста по цирконам на основе изотопной геохимии гафния и неодима (на примере некоторых магматических комплексов фундамента Восточно-Европейской платформы) // Региональная геология и металлогения. 2009. № 38. С. 43-53.

6. Чупин В.П., Ветрин В.Р. Расплавные и флюидные включения в цирконе и породообразующих минералах из плагиогнейсов архейского комплекса Кольской сверхглубокой скважины (Балтийский щит). Геохимия. 2005. № 2. С. 206-212.

7. Чупин В.П., Ветрин В.Р., Родионов Н.В., Матуков Д.И., Бережная Н.Г., Сергеев С.А., Митрофанов Ф.П., Смирнов Ю.П. Состав расплавных включений и возраст цирконов из плагиогнейсов архейского комплекса Кольской сверхглубокой скважины (Балтийский щит). Докл. АН. 2006. Т. 406. № 4. С. 533-537.

8. Чупин В.П., Ветрин В.Р., Сергеев С.А.,Бережная Н.Г., Родионов Н.В. Магматические включения в цирконе из архейских «серых гнейсов» Кольской сверхглубокой скважины как показатель происхождения и возраста протолитов. Изотопные системы и время геологических процессов. Материалы IV Российской конференции по изотопной геохронологии. СПб: ИП Каталкина. 2009. С. 266-268.

9. Thomas J.B., Bodnar R.J., Shimizu N., Chesner C.A. Melt Inclusions in Zircon. Reviews in Mineralogy and Geochemistry. 2003. V. 53. № 1. P. 63-87.

10. Vervoort J.D., Blichert-Toft J. Evolution of depleted mantle: Hf evidence from juvenile rocks through time. Geochim., Cosmochim. Acta. 1999. V. 63. N. 3/4. P. 533-556.

11. Blichert-Toft J., Albarede F. The Lu-Hf isotope geochemistry of chondrites and evolution of the mantle-crust system. Earth, Planet. Sci. Lett. 1997. V. 148. P. 243-258. 